\title{
Gas Chromatography Mass Spectrometry
}

National Cancer Institute

\section{Source}

National Cancer Institute. Gas Chromatography Mass Spectrometry. NCI Thesaurus.

Code C111203.

An analytical technique wherein gas chromatography is coupled to mass spectrometry in order to separate, identify, and quantify substances in a sample. 